\title{
iStent Trabecular Microbypass Stent Implantation with Phacoemulsification in Patients with Open-Angle Glaucoma: 6-Year Outcomes
}

This article was published in the following Dove Press journal: Clinical Ophthalmology

\author{
Tanner J Ferguson (D) \\ Keegan B Mechels' \\ Zachary Dockter ${ }^{2}$ \\ Adam Bleeker $\mathbb{D}^{2}$ \\ Mitch Ibach ${ }^{3}$ \\ Justin Schweitzer ${ }^{3}$ \\ John P Berdahl $\mathbb{1}^{3}$ \\ 'Cole Eye Institute, Cleveland Clinic, \\ Cleveland, OH, USA; ${ }^{2}$ University of \\ South Dakota Sanford School of \\ Medicine, Sioux Falls, SD, USA; ${ }^{3}$ Vance \\ Thompson Vision, Sioux Falls, SD, USA
}

Correspondence: Tanner J Ferguson Email tannerferg@gmail.com
Purpose: To investigate the long-term safety and efficacy of an iStent trabecular microbypass stent in combination with cataract surgery in eyes with primary open-angle glaucoma (POAG). Setting: Private practice; Sioux Falls, South Dakota.

Design: Retrospective, consecutive case series.

Methods: This case series included eyes implanted with a single trabecular microbypass stent in combination with phacoemulsification in patients with mild to severe POAG. Data were collected preoperatively and at day 1 , week 1 , month 1 , and up to 6 years postoperatively. Primary outcome measures included mean intraocular pressure (IOP) and number of glaucoma medications. Safety was noted by assessing the incidence of IOP spikes and need for additional surgery.

Results: The study comprised 411 eyes. Mean IOP was reduced to $14.9 \pm 4.2 \mathrm{mmHg}$ compared to $18.8 \pm 5.6 \mathrm{mmHg}$ at baseline at 6 years postoperative. The mean number of medications was reduced to $1.2 \pm 1.0$ from $1.4 \pm 1.1$ at baseline. In eyes with severe stage of disease, there was a mean IOP reduction $>6 \mathrm{mmHg}$ at 6 years postoperative. Eyes with baseline IOP $\geq 18 \mathrm{mmHg}$ achieved a more robust reduction in IOP. Fifteen eyes underwent a secondary glaucoma procedure. There were no intra- or postoperative complications.

Conclusion: Trabecular microbypass stent implantation in combination with cataract surgery provides a sustained IOP reduction in eyes with mild-to-severe POAG. The degree of IOP reduction was more significant in eyes with higher baseline IOP and severe stage of disease.

Keywords: microinvasive glaucoma surgery, MIGS, trabecular microbypass stent, surgical glaucoma, primary open-angle glaucoma

\section{Introduction}

Glaucoma is a leading cause of irreversible blindness globally, and disease burden is only expected to worsen with an estimated 111 million cases by $2040 .{ }^{1}$ Current approaches to treatment are focused on decreasing intraocular pressure (IOP), the only modifiable risk factor associated with the development and progression of open-angle glaucoma (OAG). ${ }^{2}$ Early in the disease process, ocular hypotensive pharmacotherapy has been an effective first-line treatment. ${ }^{3}$ However, topical therapies carry issues related to not only the tolerability, but also the consistency in drug administration, leading to poor compliance with therapy. ${ }^{4,5}$ While traditional surgical filtering procedures such as trabeculectomies and tube shunts remain options, they carry a significant risk profile. ${ }^{6,8}$ 
Minimally invasive glaucoma surgery (MIGS) is an established and growing space of new treatment options for primary and secondary OAG that offers a superior safety profile to traditional glaucoma procedures and can safely be combined with cataract surgery, as well as other MIGS procedures. ${ }^{9,10}$ The introduction of MIGS has stimulated a more proactive, interventional approach in the treatment of mild-to-moderate glaucoma, reducing the burden and minimizing the problems typically observed with topical glaucoma medications. ${ }^{11,12}$ MIGS procedures are safe and preserve the flexibility for future surgical intervention. $^{13,14}$ The first FDA-approved MIGS device, the trabecular microbypass stent (iStent, Glaukos Corp.), was introduced in 2012 and has been extensively studied in patients with primary open-angle glaucoma, particularly in the short-term. ${ }^{15,18}$ There have been few studies, however, reporting long-term data in these patients. ${ }^{19}$

This study aims to investigate the long-term safety and efficacy of the trabecular microbypass stent placed in combination with cataract surgery in patients with POAG with outcomes out to 6 years postoperative. As stated previously, while short-term effectiveness and safety is widely known, longer term data is scarce and minimal. This study represents a continuation and expansion of a previous retrospective, consecutive case series that provided results out to 24 months, published in $2016 .{ }^{16}$

\section{Methods}

\section{Study Design}

Consecutive patients implanted with a single trabecular microbypass stent in combination with cataract surgery were included in this retrospective case series. Patients included had a preoperative diagnosis of mild-to-severe primary open-angle glaucoma. Staging of disease was based on the American Academy of Ophthalmology preferred practice pattern guidelines consistent with optic nerve and visual field changes (mild: no changes on white-on-white 24-2; moderate: changes in one hemifield and not within 5 degrees of fixation; severe: changes in both hemifields or changes within 5 degrees of fixation in at least one hemifield). ${ }^{3}$ No cases were excluded. This study was designed to mimic typical clinical use of the device and provide real-world long-term data. This was a retrospective case series that collected data from procedures that had already occurred and was de-identified; therefore, no informed consent process was utilized. The University of South Dakota Institutional Review Board approved this study.

\section{Surgical Technique}

The surgical technique in this study is identical to what was initially described in the previous study that evaluated outcomes through 24 months postoperatively. ${ }^{16}$

\section{Postoperative Medications and Follow-Up} Postoperatively, patients were prescribed antibiotics for 1 week, a daily non-steroidal anti-inflammatory drug for 4 weeks and a topical steroid for 4 weeks. Patients were kept on their preoperative ocular hypotensive medications for at least 1 week and the decision to remove/stop medications was based on clinical judgment. As opposed to the prospective, restrictive clinical trials, no specific guidelines were utilized postoperatively to guide the decision to add or remove ocular hypotensive medications.

Preoperative data were used to establish a baseline, typically $1-2$ weeks before the surgery. Postoperatively, data were collected from the following time points to compare to baseline: 1 day, 1 week, months 1,3 , and 6 , as well as yearly out to 6 years postoperatively. At each time point, the data collected included IOP in addition to number and type of medications used. A consistent cohort group, a subgroup of eyes with 6-year data available, was also established to directly compare the eyes with 6-year postoperative data to baseline.

\section{Outcome Measures and Safety Evaluation}

The main outcome measures in the study were mean IOP as well as the mean number of ocular hypotensive (glaucoma) medications. Combination glaucoma medications (eg, dorzolamide-timolol) were logged as two medications in the data set. The baseline IOP, collected via Goldmann applanation tonometry, was obtained from the visit immediately prior to surgery and was based on a single measure. To evaluate the safety of the procedure, the need for additional surgery was noted in addition to the incidence of IOP spikes above baseline greater than or equal to 15 $\mathrm{mmHg}$ at any time point postoperatively. The type of secondary glaucoma procedure was also noted and eyes that underwent an additional procedure were included in the data set until the point of secondary intervention.

\section{Statistical Analyses}

A parametric paired $t$-test procedure was used to determine the significance of the mean change in IOP from baseline to all time points 6 months postoperatively (eg, 1 year, 2 years, etc.). To compare the mean change in the number of glaucoma medications, parametric paired $t$-test procedures were 
also employed to compare values at baseline versus postoperative time points. All the statistical analyses in this paper were carried out using SAS software (Version 9.4, SAS Institute, Cary, NC, USA). An $\alpha$ level of 0.05 was considered statistically significant.

\section{Results}

This retrospective, consecutive case series included 411 eyes in a clinical, real-world setting that underwent successful implantation of one trabecular microbypass stent (iStent) in combination with cataract surgery. At 6 years postoperatively, data was available for 120 of the 411 eyes included at baseline. In the data set, 247 of the 411 eyes were female and 164 were male. Table 1 demonstrates a summary of the preoperative characteristics of the study population.

\section{Efficacy: Intraocular Pressure and Medications}

Figure 1 shows the mean IOP and number of glaucoma medications for all eyes included in the retrospective chart review. Through 6 years postoperatively, the mean IOP and

Table I This Table Demonstrates Baseline Subject Characteristics of All Eyes Included in the Study. Preoperative Characteristics

\begin{tabular}{|l|l|}
\hline Parameter & \\
\hline Age, years (Mean, SD) & $76.7 \pm 8.8$ \\
Gender (M/F) & $247 \mathrm{~F} / 164 \mathrm{M}$ \\
\hline No. of medications & \\
Mean (SD) & $1.4(\mathrm{I} .1)$ \\
No. on 0 meds & $97(24 \%)$ \\
No. on I meds & $155(38 \%)$ \\
No. on 2 meds & $81(20 \%)$ \\
No. on 3 meds & $65(16 \%)$ \\
No. on 4 meds & $13(3 \%)$ \\
\hline Mild OAG & \\
Mean Preop meds $(\mathrm{n}) \pm \mathrm{SD}$ & $1.1 \pm 1.0$ \\
Mean Preop IOP $(\mathrm{mm} \mathrm{Hg})$ & $19.0 \pm 5.5$ \\
eyes $(\mathrm{n})$ & 234 \\
\hline Moderate OAG & \\
Mean Preop meds $(\mathrm{n}) \pm \mathrm{SD}$ & $1.4 \pm 0.9$ \\
Mean Preop IOP $(\mathrm{mm} \mathrm{Hg}) \pm \mathrm{SD}$ & $17.8 \pm 4.9$ \\
eyes (n) & 93 \\
\hline Severe OAG & $2.1 \pm 1.3$ \\
Mean Preop meds $(\mathrm{n}) \pm \mathrm{SD}$ & $19.3 \pm 6.4$ \\
Mean Preop IOP $(\mathrm{mm} \mathrm{Hg}) \pm \mathrm{SD}$ & 84 \\
eyes (n) & \\
\hline
\end{tabular}

Abbreviations: IOP, intraocular pressure; OAG, open-angle glaucoma; $O D$, right; OS, left. number of medications were collected and analyzed at each postoperative time point. At baseline, the mean IOP was 18.8 $\pm 5.6 \mathrm{mmHg}$ and the mean number of glaucoma medications was $1.4 \pm 1.1$. At 6 months postoperatively, the IOP was 14.9 $\pm 3.9 \mathrm{mmHg}(P<0.01)$. This reduction was largely sustained with the mean IOP remaining $<15.5 \mathrm{mmHg}$ at each time point out to 6 years after surgery with a mean IOP of 14.9 $\pm 4.2 \mathrm{mmHg}(P<0.01)$. For medication use, the mean number of medications was $0.7 \pm 1.0$ at 1 year postoperatively. At 3 years postoperatively, the mean number of medications was $0.9 \pm 1.1$, increased from $0.8 \pm 1.1$ at 2 years postoperatively. At 6 years postoperatively, the mean number of medications was $1.2 \pm 1.0(P>0.05)$.

This study utilized a consistent cohort to directly compare the eyes with data available at 6 years postoperative to baseline. The mean IOP and glaucoma medications for the consistent cohort is shown in Figure 2. In this cohort, the baseline characteristics included a mean IOP of $18.6 \pm 6.4$ $\mathrm{mmHg}$ and a mean of $1.6 \pm 1.1$ medications. At 3 years postoperatively, the mean number of medications was 1.1 \pm 1.0 and the mean IOP was $15.3 \pm 3.7 \mathrm{mmHg}$. Six years after surgery, the mean IOP was reduced from baseline by $20 \%$ to $14.9 \pm 4.2$ and the mean number of drops was 1.2 \pm 1.1 . In the consistent cohort, eyes on $\geq 1$ medication(s) at baseline decreased the number of medications from a mean of $1.9 \pm 0.9$ at baseline to $1.4 \pm 1.1$ at 6 years postoperative. In addition, eyes in the consistent cohort with a baseline IOP $\geq 18 \mathrm{mmHg}$ had a year 6 mean IOP of $15.9 \pm 4.7$ compared to $23.2 \pm 5.9 \mathrm{mmHg}$ at baseline.

This study also stratified results based on baseline IOP, baseline number of medications, and glaucoma severity. In eyes with a baseline IOP $\geq 18 \mathrm{mmHg}$, the mean IOP prior to surgery was $22.5 \pm 4.6 \mathrm{mmHg}$. At 1 year postoperatively, the mean IOP was $16.6 \pm 4.2 \mathrm{mmHg}$ and this reduction in pressure was maintained to 6 years postoperatively with a mean IOP of $15.9 \pm 4.7 \mathrm{mmHg}(P<0.01)$. For medication use in this cohort, the mean number of medications was $1.0 \pm 1.0(P>0.05)$ at 6 years postoperatively, down from $1.3 \pm 1.1$ at baseline.

As mentioned previously, primary open-angle glaucoma severity was staged based on the AAO preferred practice pattern guidelines. In eyes with mild $(n=234)$ stage of disease, prior to the surgery, the mean IOP was $19.0 \pm 5.5$ and the mean number of medications was $1.1 \pm 1.0$. At 3 years postoperative, mean IOP was $15.9 \pm 3.8(P<0.01)$ and medications were reduced to $0.6 \pm 1.0(P<0.05)$. At 6 years after surgery, the mean IOP was $16.4 \pm 3.9 \mathrm{mmHg}(14 \%$ reduction from baseline) and the mean number of drops was $0.9 \pm 1.0$ $(P>0.05)$. In the moderate $(n=93)$ stage of the disease 


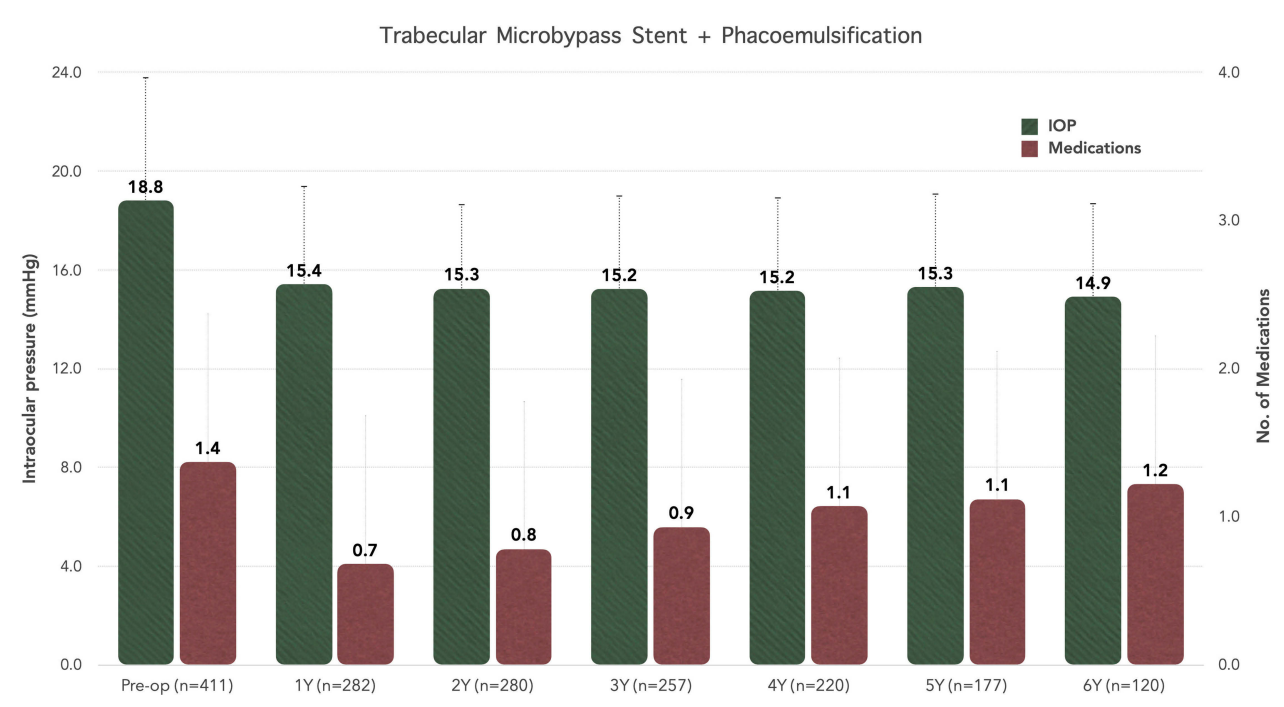

Figure I This figure demonstrates the mean IOP and number of glaucoma medications for all eyes included in the study out to 6 years postoperative. The error bars represent standard deviation.

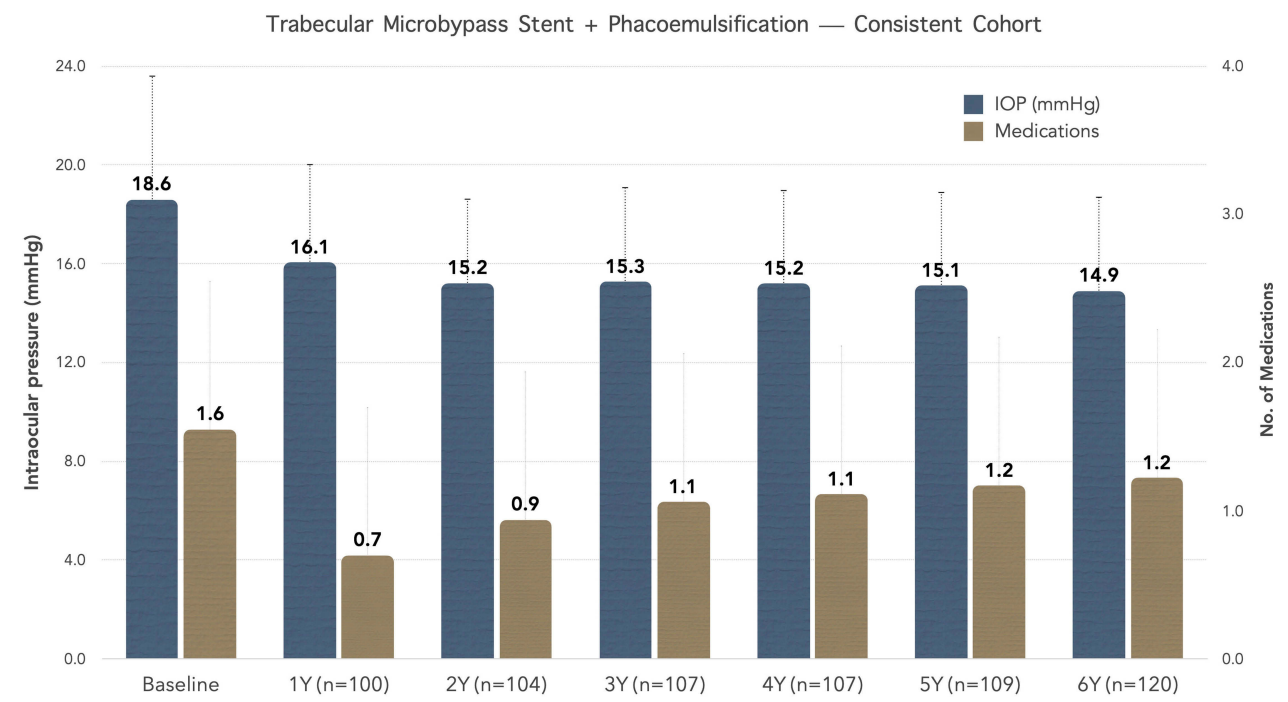

Figure 2 The mean IOP and number of glaucoma medications is shown for eyes in the consistent cohort. The consistent cohort is composed of eyes with 6-year data available and was established to directly compare this subset to baseline. The error bars represent standard deviation.

subgroup, the mean year 6 IOP was reduced to $13.3 \pm 3.9$ $(P<0.01) \mathrm{mmHg}(25 \%$ reduction) compared to $17.8 \pm 4.9$ $\mathrm{mmHg}$ at baseline and the year 6 number of medications was $1.3 \pm 1.0(P>0.05)$ versus $1.4 \pm 0.9$ at baseline. In the severe $(\mathrm{n}=84)$ POAG subgroup, the mean IOP at 6 years was $13.0 \pm 3.9(P<0.01) \mathrm{mmHg}$ compared to $19.3 \pm 6.4 \mathrm{mmHg}$ at baseline (33\% reduction); the mean number of medications at 6 years was $1.7 \pm 1.3(P>0.05)$, down from $2.1 \pm 1.3$ at baseline. Figure 3 shows the comparison of IOP and medication reduction stratified by disease severity.

In the subset of eyes $(n=159)$ being actively treated with $\geq 2$ medication(s) at baseline, the year 6 mean number of medications was $1.7 \pm 1.2(P<0.01)$, down from $2.6 \pm 0.7$ preoperatively ( $35 \%$ reduction). In the subgroup of eyes with $\geq 3$ glaucoma medications preoperatively, the mean medication burden was reduced to $2.0 \pm 1.0 \quad(P<0.01)$ at year 6 compared to $3.2 \pm 0.6$ preoperatively (1.2 medication decrease). In eyes not being treated with medication prior to the surgery, the mean number of medications was increased to $0.5 \pm 0.7$ at 6 years postoperatively.

Proportional IOP analyses were also performed. At baseline, $59 \%$ of eyes had a baseline value $\leq 18 \mathrm{mmHg}$ and $26 \%$ had baseline IOP $\leq 15 \mathrm{mmHg}$. By 1 year postoperative, the proportion of eyes with $\leq 18 \mathrm{mmHg}$ increased to $81 \%$ and the 
Mean IOP by Glaucoma Severity

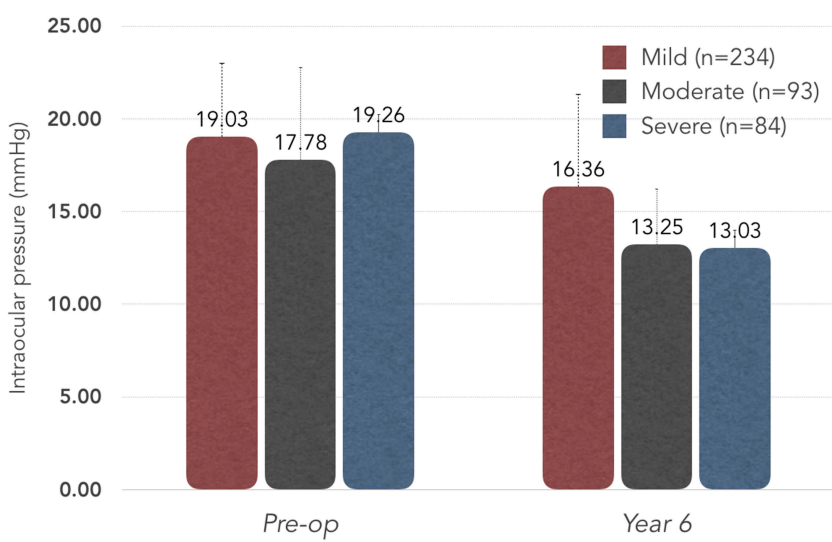

Mean No. of Medications by Glaucoma Severity

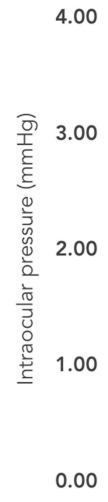

0.00

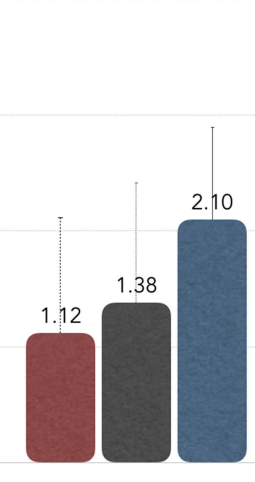

Pre-op
Mild ( $\mathrm{n}=234)$

Moderate $(n=93)$

Severe $(n=84)$

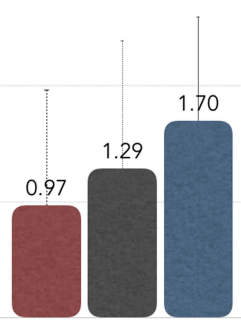

Year 6

Figure 3 This figure demonstrates the mean IOP and number of glaucoma medications stratified by glaucoma severity at baseline and 6 years postoperative. The graph on the left compares mean IOP and the graph on the right compares mean number of glaucoma medications.

proportion of eyes with $\leq 15 \mathrm{mmHg}$ increased to $53 \%$. In both subgroups, these values demonstrated stability out to 6 years postoperative with $83 \%$ of eyes at $\leq 18 \mathrm{mmHg}$ and $53 \%$ of eyes remaining at $\leq 15 \mathrm{mmHg}$. These results are shown in Figure 4.

The magnitude of IOP reduction was also evaluated based on the baseline IOP in the consistent cohort (eyes with 6 year data available). To compare the magnitude of IOP reduction, the 6 year IOP was logged and compared to baseline. In eyes with a baseline IOP of $18-20 \mathrm{mmHg}$ $(\mathrm{n}=23)$, the mean reduction in pressure was $3.6 \mathrm{mmHg}$ at 6 years. In the subset of eyes with a baseline IOP $\geq 21$ $\mathrm{mmHg}(\mathrm{n}=36)$, the mean reduction in IOP was 9.7
$\mathrm{mmHg}$, more than double than was observed in eyes with a baseline IOP $18-20 \mathrm{mmHg}$. Eyes with a baseline IOP $<18 \mathrm{mmHg}$ did not achieve a meaningful reduction in IOP at 6 years postoperatively with a $0.2 \mathrm{mmHg}$ decrease in pressure.

\section{Safety Profile}

All patients included in the study had successful implantation of the device without perioperative complications. Over the 6-year follow-up period, no patients had sight-threatening complications including no hypotony, maculopathy, retinal detachment, or endophthalmitis. Twenty-five (6\%) eyes had an of IOP increase $\geq 15 \mathrm{mmHg}$ above baseline in the

\section{Proportional Analyses: IOP $\leq 15 \mathrm{mmHg}$ and IOP $\leq 18 \mathrm{mmHg}$}

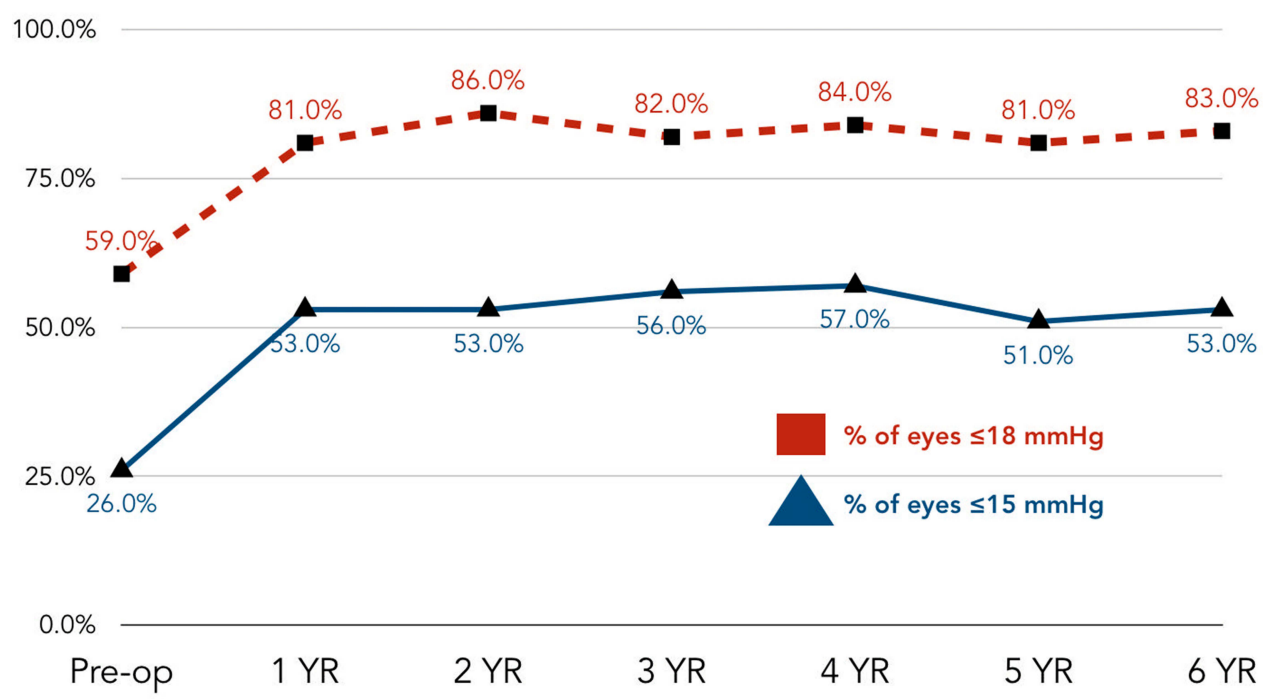

Figure 4 This figure demonstrates the IOP proportional analyses including the percentage of eyes at each time point with $I O P \leq I 5 \mathrm{mmHg}$ and IOP $\leq \mathrm{I} 8 \mathrm{mmHg}$. 
postoperative period, most of which occurred in the first month postoperatively and responded to topical therapy. Fifteen eyes (4\%) underwent a secondary glaucoma procedure, with nine undergoing a secondary MIGS procedure and six undergoing a filtering procedure. No other ocular adverse events were identified postoperatively. Specifically, there were no reports of stent obstruction, hypotony, or inflammatory sequelae such as peripheral anterior synechiae.

For visual outcomes, at 6 years postoperative, 94\% of eyes had corrected-distance visual acuity (CDVA) of 20/40 or better. Additionally, $75 \%$ of eyes achieved a vision of 20/25 CDVA or better at this time point.

During the 6-year follow-up period, 26 of the eyes included in the study died, all of which were unrelated to implantation of the device.

\section{Discussion}

The introduction of MIGS has altered the management of open-angle glaucoma, particularly those with mild-moderate stage of disease needing additional IOP reduction not achievable with conservative treatment options, but do not yet warrant the need for an aggressive filtering procedure and associated risks. ${ }^{20}$ MIGS has been demonstrated to be of particular value for reducing medication use. Owing to the recognized side effects of topical medication use and the reduced adherence with $>1$ drop, reduction of the medication burden in any capacity has long-term benefits for patients. $^{21,23}$ Over the past decade, the MIGS category has grown immensely with devices targeting different anatomical regions for IOP reduction, enabling clinicians to provide an individualized approach to treatment. The wealth of options currently available may contribute to indecision from clinicians when choosing a procedure and, thus, it remains critical to continue investigating the different devices to identify whether certain patient- or diseasespecific factors exist to tailor the MIGS device selection process. $^{10,13}$

The short-term safety and efficacy of the trabecular microbypass stent in combination with cataract surgery is well documented by numerous studies; however, longterm data is scarce with the vast majority of studies demonstrating outcomes out to 12-36 months postoperative. ${ }^{17,24,26}$ Given the significant risks associated with traditional filtering glaucoma surgery as well as the propensity of the initial IOP reduction in laser trabeculoplasty to fade with time, the long-term data from these studies are of increasing utility. ${ }^{6,8,27,28}$ This study contains results out to six years post-operatively, making it one of the longest follow-up periods to date for trabecular microbypass stents in eyes with open-angle glaucoma. This study includes eyes with mild-to-severe stage of disease and the large sample size permitted comparison of the safety/efficacy of the procedure based on disease severity. Given the lack of studies evaluating MIGS devices in severe stage of open-angle glaucoma, ${ }^{29}$ the results of this study also provide additional insight into the use of MIGS in this patient population.

The study preceding this long-term study showed a meaningful reduction in IOP and medication use out to 24 months postoperatively. ${ }^{16}$ The results of this present study highlight the sustainable IOP-lowering ability of the trabecular microbypass stent in combination with cataract surgery with results out to 6 years postoperatively. In this study, the mean IOP at 6 years was $14.9 \pm 4.2 \mathrm{mmHg}$ and the IOP remained $<15.5 \mathrm{mmHg}$ at all time points postoperatively, down from $18.8 \pm 5.6 \mathrm{mmHg}$ at baseline, demonstrating the sustained pressure reduction. Furthermore, the proportion of eyes with IOP $\leq 15 \mathrm{mmHg}$ at 1 year $(53 \%)$ was maintained and stable through 6 years postoperative. For medication use, although there was an overall decrease in the medication burden at 6 years postoperative, there was an upward trend of medication use starting at 3 years postoperative. At 2 and 3 years postoperative, the mean number of medications was $0.9 \pm 1.1$ and $1.1 \pm 1.0$, respectively. At the year 6 time point, the mean number of medications was $1.2 \pm 1.1$, down $21 \%$ from baseline. The long-term results of this study also highlight the use of this device in eyes with severe stage of disease, which has been previously demonstrated out to 24 months postoperative in a prior study exclusively evaluating severe POAG from the same practice. In this present study, there was an impressive IOP reduction, $>6$ $\mathrm{mmHg}$, in this population down to $13.0 \pm 3.9 \mathrm{mmHg}$ at 6 years postoperative.

With respect to the long-term safety of this procedure, the safety profile observed through 6 years was not markedly dissimilar than what was demonstrated through the first 24 months. The short-term safety profile of the trabecular microbypass stent has been corroborated by multiple studies. ${ }^{15,26}$ The long-term data is important as the trabecular microbypass stent avoids the well-documented later complications of filtering surgeries (ie, bleb-related issues, hypotony, astigmatism). ${ }^{30,31}$ Long-term safety is important to consider and recognize as quality-of-life is proposed as a notable benefit of the MIGS procedures, particularly with respect to the trabecular microbypass stent. ${ }^{10}$ 
The IOP-lowering benefit of cataract surgery alone has been established by numerous studies ${ }^{32}$ including the Ocular Hypertension Treatment Study (OHTS). ${ }^{33}$ In the OHTS trial, patients undergoing phacoemulsification alone achieved a $17 \%$ decrease in IOP and the reduction in IOP was proportional to baseline IOP with eyes $<22.3 \mathrm{mmHg}$ achieving an $11 \%$ reduction in IOP. In the OHTS trial, the mean baseline IOP was $23.9 \mathrm{mmHg}$, which makes it difficult to compare to the results of this study given the lower baseline IOP in our study $(18.8 \mathrm{mmHg})$. However, recognizing that IOP reduction is proportional to baseline IOP, the $20 \%$ reduction at 6 years from baseline in the consistent cohort in this study suggests the trabecular microbypass stent augments the IOP reduction observed with phacoemulsification alone, which is consistent with prior studies demonstrating the IOP-lowering ability of the stent alone. ${ }^{24,34}$

While these results continue to be promising for the treatment of OAG, this study is not without limitations. The design of this study was open-label and nonrandomized. It was also retrospective in nature which prohibits a uniform follow-up pattern that contributes to missing data at specific time points. The loss to follow-up is a drawback of the study and it's possible that patients lost to follow-up may have undergone an additional procedure elsewhere which limits our conclusions related to the long-term safety profile of the device. However, given that this was a retrospective case series ranging from 2012 to 2015 , over $30 \%$ of cases were taken from 2014/2015 and thus 6-year data was not available for these eyes. Despite these limitations, this study provides a large sample size and the longest follow-up data to date evaluating the safety and efficacy of this device in conjunction with cataract surgery. Moreover, this study was a consecutive case series that did not utilize inclusion or exclusion criteria and is representative of a typical clinician's real-world patient population.

To our knowledge, this long-term study presents the longest follow-up data of a study evaluating the iStent trabecular microbypass stent and represents the largest sample size published to date with $>400$ eyes included. The large sample size of this study enabled stratification of results based on glaucoma severity and baseline characteristics that provides valuable insight. The findings of this study support the use of the device in mild-to-severe stage of disease. Moreover, eyes with a higher baseline IOP (eg, $\geq 18 \mathrm{mmHg}$ ) achieve a more robust reduction in IOP. Despite being retrospective, this study provides important insight regarding the long-term safety and efficacy of the trabecular microbypass stent in combination with cataract surgery.

\section{Acknowledgment}

This work was presented at the 2019 American Society of Cataract and Refractive Surgeons (ASCRS) Annual Meeting, San Diego, CA, USA.

\section{Funding}

Investigator-initiated trial grant from Glaukos Corp. (San Clemente, CA).

\section{Disclosure}

Drs. Ferguson, Ibach, Schweitzer, and Berdahl are consultants and speakers for Glaukos Corp. Tanner J Ferguson reports personal fees from Glaukos outside the submitted work and consultancy for Equinox Ophthalmic, Inc. Mitch Ibach reports consulting and lecture honoraria from Glaukos outside the submitted work. Justin Schweitzer reports personal fees from Glaukos during the conduct of the study and outside the submitted work and consultant and lecturer honorarium from Glaukos. John P Berdahl reports grants from Glaukos during the conduct of the study and personal fees from Glaukos outside the submitted work. The authors report no other possible conflicts of interest in this work.

\section{References}

1. Tham Y-C, Li X, Wong TY, Quigley HA, Aung T, Cheng C-Y. Global prevalence of glaucoma and projections of glaucoma burden through 2040: a systematic review and meta-analysis. Ophthalmology. 2014;121(11):2081-2090. doi:10.1016/j.ophtha.2014.05.013

2. Heijl A, Leske MC, Bengtsson B, et al. Reduction of intraocular pressure and glaucoma progression: results from the early manifest glaucoma trial. Arch Ophthalmol. 2002;120(10):1268-1279. doi:10.10 01/archopht.120.10.1268

3. Prum BE, Rosenberg LF, Gedde SJ, et al. Primary open-angle glaucoma preferred practice pattern(®) guidelines. Ophthalmology. 2016;123:p41-111. doi:10.1016/j.ophtha.2015.10.053

4. Boland MV, Ervin A-M, Friedman DS, et al. Comparative effectiveness of treatments for open-angle glaucoma: a systematic review for the U.S. preventive services task force. Ann Intern Med. 2013;158 (4):271-279. doi:10.7326/0003-4819-158-4-201302190-00008

5. Tsai JC. A comprehensive perspective on patient adherence to topical glaucoma therapy. Ophthalmology. 2009;116(11 Suppl):S30-6. doi:10. 1016/j.ophtha.2009.06.024

6. Jampel HD, Musch DC, Gillespie BW, Lichter PR, Wright MM, Guire KE. Perioperative complications of trabeculectomy in the collaborative initial glaucoma treatment study (CIGTS). Am J Ophthalmol. 2005;140(1):16-22. doi:10.1016/j.ajo.2005.02.013

7. Chen J, Gedde SJ. New developments in tube shunt surgery. Curr Opin Ophthalmol. 2019;30(2):125-131. doi:10.1097/ICU.0000000000000549

8. Rulli E, Biagioli E, Riva I, et al. Efficacy and safety of trabeculectomy vs nonpenetrating surgical procedures: a systematic review and meta-analysis. JAMA Ophthalmol. 2013;131(12):1573-1582. doi:10. 1001/jamaophthalmol.2013.5059

9. Lavia C, Dallorto L, Maule M, Ceccarelli M, Fea AM. Minimallyinvasive glaucoma surgeries (MIGS) for open angle glaucoma: a systematic review and meta-analysis. PLoS One. 2017;12(8): e0183142. doi:10.1371/journal.pone.0183142 
10. Shah M. Micro-invasive glaucoma surgery - an interventional glaucoma revolution. Eye Vis Lond Engl. 2019;6(1):29. doi:10.1186/ s40662-019-0154-1

11. Tsai T, Robin AL, Smith JP. An evaluation of how glaucoma patients use topical medications: a pilot study. Trans Am Ophthalmol Soc. 2007;105:29-33; discussion 33-35.

12. Gupta R, Patil B, Shah BM, Bali SJ, Mishra SK, Dada T. Evaluating eye drop instillation technique in glaucoma patients. J Glaucoma. 2012;21(3):189-192. doi:10.1097/IJG.0b013e31820bd2e1

13. Saheb H, Ahmed I, Micro-invasive glaucoma surgery: current perspectives and future directions. Curr Opin Ophthalmol. 2012;23 (2):96-104. doi:10.1097/ICU.0b013e32834ffle7

14. Grace M, Richter ALC. Minimally invasive glaucoma surgery: current status and future prospects. Clin Ophthalmol Auckl NZ. 2016;10:189-206. doi:10.2147/OPTH.S80490

15. Craven ER, Katz LJ, Wells JM, Giamporcaro JE. Cataract surgery with trabecular micro-bypass stent implantation in patients with mild-to-moderate open-angle glaucoma and cataract: two-year follow-up. J Cataract Refract Surg. 2012;38(8):1339-1345. doi:10. 1016/j.jcrs.2012.03.025

16. Ferguson TJ, Berdahl JP, Schweitzer JA, Sudhagoni RG. Clinical evaluation of a trabecular microbypass stent with phacoemulsification in patients with open-angle glaucoma and cataract. Clin Ophthalmol Auckl NZ. 2016;10:1767-1773. doi:10.2147/OPTH.S114306

17. Vold SD, Voskanyan L, Tetz M, et al. Newly diagnosed primary open-angle glaucoma randomized to 2 trabecular bypass stents or prostaglandin: outcomes through 36 months. Ophthalmol Ther. 2016;5(2):161-172. doi:10.1007/s40123-016-0065-3

18. Samuelson TW, Katz LJ, Wells JM, Duh Y-J, Giamporcaro JE. Randomized evaluation of the trabecular micro-bypass stent with phacoemulsification in patients with glaucoma and cataract. Ophthalmology. 2011;118(3):459-467. doi:10.1016/j.ophtha.2010.07. 007

19. Neuhann TH, Hornbeak DM, Neuhann RT, Giamporcaro JE. Longterm effectiveness and safety of trabecular microbypass stent implantation with cataract surgery in patients with glaucoma or ocular hypertension: five-year outcomes. J Cataract Refract Surg. 2019;45 (3):312-320. doi:10.1016/j.jcrs.2018.10.029

20. Shah M, Law G, Ahmed IIK. Glaucoma and cataract surgery. Curr Opin Ophthalmol. 2016;27(1):51-57. doi:10.1097/ICU.0000000000 000224

21. Baudouin C, Renard J-P, Nordmann J-P, et al. Prevalence and risk factors for ocular surface disease among patients treated over the long term for glaucoma or ocular hypertension. Eur $J$ Ophthalmol. 2012;23(1):47-54. doi:10.5301/ejo.5000181

22. Baudouin C, Liang H, Hamard P, et al. The ocular surface of glaucoma patients treated over the long term expresses inflammatory markers related to both T-helper 1 and T-helper 2 pathways. Ophthalmology. 2008;115(1):109-115. doi:10.1016/j.ophtha.2007. 01.036
23. Robin AL, Novack GD, Covert DW, Crockett RS, Marcic TS. Adherence in glaucoma: objective measurements of once-daily and adjunctive medication use. Am J Ophthalmol. 2007;144(4):533-540. doi:10.1016/j.ajo.2007.06.012

24. Donnenfeld ED, Solomon KD, Voskanyan L, et al. A prospective 3-year follow-up trial of implantation of two trabecular microbypass stents in open-angle glaucoma. Clin Ophthalmol Auckl NZ. 2015;9:2057-2065. doi:10.2147/OPTH.S91732

25. Belovay GW, Naqi A, Chan BJ, Rateb M, Ahmed IIK. Using multiple trabecular micro-bypass stents in cataract patients to treat open-angle glaucoma. J Cataract Refract Surg. 2012;38(11):19 11-1917. doi:10.1016/j.jcrs.2012.07.017

26. Myers JS, Masood I, Hornbeak DM, et al. Prospective evaluation of two istent ${ }^{\circledR}$ trabecular stents, one istent supra ${ }^{\circledR}$ suprachoroidal stent, and postoperative prostaglandin in refractory glaucoma: 4-year outcomes. Adv Ther. 2018;35(3):395-407. doi:10.1007/s12325-0180666-4

27. Juzych MS, Chopra V, Banitt MR, et al. Comparison of long-term outcomes of selective laser trabeculoplasty versus argon laser trabeculoplasty in open-angle glaucoma. Ophthalmology. 2004;111 (10):1853-1859. doi:10.1016/j.ophtha.2004.04.030

28. Neuhann TH. Trabecular micro-bypass stent implantation during small-incision cataract surgery for open-angle glaucoma or ocular hypertension: long-term results. J Cataract Refract Surg. 2015;41 (12):2664-2671. doi:10.1016/j.jcrs.2015.06.032

29. Ferguson T, Swan R, Ibach M, Schweitzer J, Sudhagoni R, Berdahl JP. Evaluation of a trabecular microbypass stent with cataract extraction in severe primary open-angle glaucoma. J Glaucoma. 2018;27(1):71-76. doi:10.1097/IJG.0000000000000825

30. Delbeke H, Stalmans I, Vandewalle E, Zeyen T. The effect of trabeculectomy on astigmatism. J Glaucoma. 2016;25(4):e308-e312. doi:10.1097/IJG.0000000000000236

31. Higashide T, Ohkubo S, Sugimoto Y, Kiuchi Y, Sugiyama K. Persistent hypotony after trabeculectomy: incidence and associated factors in the collaborative bleb-related infection incidence and treatment study. Jpn J Ophthalmol. 2016;60(4):309-318. doi:10.1007/ s10384-016-0450-4

32. Poley BJ, Lindstrom RL, Samuelson TW. Long-term effects of phacoemulsification with intraocular lens implantation in normotensive and ocular hypertensive eyes. J Cataract Refract Surg. 2008;34 (5):735-742. doi:10.1016/j.jcrs.2007.12.045

33. Mansberger SL, Gordon MO, Jampel H, et al. Reduction in intraocular pressure after cataract extraction: the ocular hypertension treatment study. Ophthalmology. 2012;119(9):1826-1831. doi:10.1016/j. ophtha.2012.02.050

34. Ferguson TJ, Ibach M, Schweitzer J, et al. Trabecular microbypass stent implantation in pseudophakic eyes with open-angle glaucoma: long-term results. J Cataract Refract Surg. 2019;45(4):414-420. doi:10.1016/j.jcrs.2012.03.025
Clinical Ophthalmology

\section{Publish your work in this journal}

Clinical Ophthalmology is an international, peer-reviewed journal covering all subspecialties within ophthalmology. Key topics include: Optometry; Visual science; Pharmacology and drug therapy in eye diseases; Basic Sciences; Primary and Secondary eye care; Patient Safety and Quality of Care Improvements. This journal is indexed on PubMed
Central and CAS, and is the official journal of The Society of Clinical Ophthalmology (SCO). The manuscript management system is completely online and includes a very quick and fair peer-review system, which is all easy to use. Visit http://www.dovepress.com/ testimonials.php to read real quotes from published authors.

\section{Dovepress}

